\title{
LeaderTICE: A Platforms Recommendation System Based on a Comparative and Evaluative Study of Free E-learning Platforms
}

\author{
https://doi.org/10.3991/ijoe.v14i01.7865 \\ Mohammed Ouadoud( $\left.{ }^{\square}\right)$, Mohamed Yassin Chkouri, Amel Nejjari \\ Abdelmalek Essaadi University (UAE), Tetouan, Morocco \\ mohammed.ouadoud@gmail.com
}

\begin{abstract}
E-learning platforms are constantly changing; they have transformed the life of teachers and students. In this paper, we propose a comparative study of free e-learning platforms, from a methodical and systemic approach that identifies the dimensions, the specifications and the essential criteria for evaluating platforms. In addition, we evaluate the most recognized elearning platforms in order to measure the match degree between technological possibilities that they offer and the pedagogical training assumptions. Eventually, we exploit the obtained results for the recommendation of free e-learning platforms since the LeaderTICE system that we implemented, in order to facilitate the choice of the most suitable e-learning platform to help the users in their choice to benefit of the potential offered by technologies in pedagogy.
\end{abstract}

Keywords-comparative study, evaluative study, e-learning platform, LMS, recommendation system, LeaderTICE

\section{$1 \quad$ Introduction}

In the digital age, universities and companies are increasingly concerned about the quality of the training they offer their students or employers in order to ensure their integration into the labor market or in the company. Moreover, distance learning helps students and teachers in their research, in the exploration and the deepening knowledge content. Thus, it helps to communicate, and interact without taking the spatial or temporal constraints between tutors and learners into consideration. Universities contributes widely to ensure the quality of courses, and help solving the problem of overcrowding in terraces. Especially, Moroccan and international universities suffer from overpopulation between student ranks, and this is due to the schooling high rate in recent years. In this respect, national and international reflections are looking for a new smart platform that are able to diffuse innovative trainings in the context of teaching and learning where a large place is given to the distance and hybrid learning, mobile learning, to using the web tools, and social networks.

Any platform choice, must meet specific requirements. This is both to present courses on the web, do homework, provide communication interfaces and be able to follow the learners through scheduled pedagogical tasks. 
In such proliferation context of the e-learning platforms, the choice becomes difficult. Consequently, any random choice causes a loss of money, effort and time. Indeed, several comparative studies on e-learning platforms have been developed previously $[27,26,21,13,12,9,8,22,7]$, but they have been abandoned because the lifecycle of the e-learning platforms is evolving apace. Therefore, we conducted a comparative study of the existing on free e-learning platforms in use in teaching and learning in order to choosing the most suitable platform.

On one side, the choosing process a free e-learning platform is related to the benefit it can bring to the training of learners. It is at the level of the mediatisation quality of didactic and pedagogical resources and access to distance trainings that were only possible in presential. On the other side, it should be noted that if the technology is supposed to address the spatial and temporal constraints between tutors and learners, it must not hinder the learning process.

This double constraint pushed us to issue the following questions:

- On one hand, how can we choose an e-learning platform that meets the norms and standards as they are acknowledged in the distance education device?

- On the other hand, what norms and standards do the requirements meet in evaluation of these platforms? Which approach in terms of pedagogical multimedia engineering should we use to assess these platforms?

These issues are the subject of the investigations as part of our study, in order to put the item on the question of the provisions. What we are proposing is an approach that allows us to make the right choice of the e-learning platform from an evaluative comparative study, technical and pedagogical of its e-learning platforms. To our knowledge, there is no kind of study that has been conducted. What makes this important for the educational community, which works for the development of approaches, methods and tools, to advance research in the education context. This paper mainly consists of five sections:

- First section (free e-learning platform) presents the definition and the benefits of elearning platforms.

- Second section (evaluation methodology) presents the selected platforms and the approach used for the evaluation. Then, it specifies the chosen rating method, and gives a description for each rating score.

- In the third section (platforms' comparison), we put the selected platforms in comparison.

- In the fourth section (platforms' evaluation), we are putting the obtained results in contribution.

- Last section (LeaderTICE recommendation system) explains how the LeaderTICE recommendation system works. 


\section{Free e-learning platforms}

\subsection{Definition}

An LMS (Learning Management System) or e-learning platform is a software including a range of services that assist teachers with the management of their courses. It offers many services allowing the management of content, particularly by creating, importing and exporting learning objects. The set of the available tools in the LMS represent all these services that help in managing the teaching process and the interaction between users such as the access control services, synchronous and asynchronous tools of communication and user administration services.

Moreover, as defined by the OVAREP (Observatoire des ressources multimédias), the e-learning platform, especially LMS, is a computing device that groups several tools and ensures the educational lines. Across dedicated platforms to the ODL (open and distance learning), all conduits are preserved and expanded for the learner, tutor, coordinator and administrator within the e-learning platform [22].

It should be mentioned, that a free e-learning platform is a software, which the use, the study, the modification and the duplication with a view to release or diffuse it are permitted, technically and legally [3]. This is to ensure certain freedoms that are induced, which include the program's control by the user and the sharing possibility between individuals [2]. These rights may simply be available or established by a license, called "free" based on copyright.

Figure 1 illustrates the general principle of the operation of an e-learning platform LMS by presenting the key features associated with the main actors: learners, teachers, tutors, coordinators, and administrators. The learner can consult and/or download the resources placed at his/her disposal by the teacher, he/she can create his/her learning activities while following his/her progress in training. The teacher, who is responsible for one or more modules, can create and manage the educational content he/she wishes to broadcast via the platform. The tutor accompanies and monitors each learner by providing the tools of communication and collaboration. Concerning the coordinator, they ensure the management of the overall system. Finally, the administrator is responsible for the customization of the platform having the rights of the administration deriving from it (system installation, maintenance, access management...).

\subsection{Benefits of free e-learning platforms}

E-learning platforms on which we count increasingly as a means of learning have considerable potential in knowledge building and skills development. Through the various services that these e-learning platforms offer, individuals can access and use multiple sources of information, available interactively at anytime and anywhere, compose personalized training paths and therefore develop the higher level skills according to their needs $[30,10]$.

For many years, universities have preferred proprietary platforms to meet the needs in new platforms. However, platforms that interest us are free e-learning platforms, because their costs, their states of development, their directions and used technologies are very close to this study axis. 


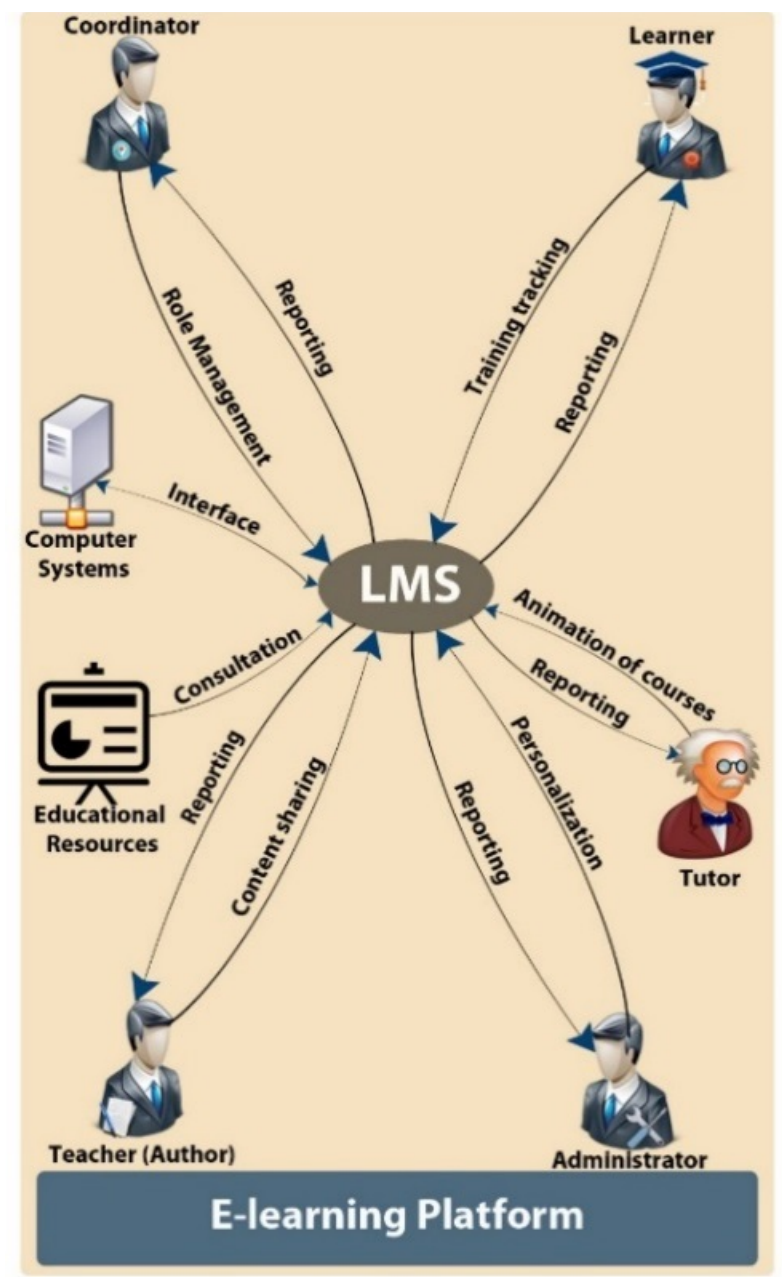

Fig. 1. The general architecture of an LMS

Today, the multitude of free e-learning platforms available, their recognized robustness makes the assembly process much more alluring. You have at your disposal dozens of free e-learning platforms that you can for the most part, simply download. This allows you to evaluate and test the components you need quickly without having to engage in a traditional buying process too long often, constraining and expensive. Free platforms also allow you to test and deploy a solution without purchasing licenses. The major advantages of free e-learning platforms are:

- the implementation speed,

- the reduction of your costs,

- Access to the source code allowing a total customization and facilitating support,

- Independence in relation to suppliers. 
Free platforms are designed, developed and tested in a highly modular way. The different parts of a platform can all be assembled and disassembled at your leisure in another platform. Free platforms are particularly well suited to the unique case, customization and some institutions specific needs. Therefore, we have listed below some advantages of free e-learning platforms.

- Easy deployment. You can install it in as many desired locations without making a particular follow-up.

- No black box. The teams can explore the source code to actually understand the platform operation.

- Independence towards editors. The evolutions of a free platform, like its updates, rely on a community of developers and not a single editor.

- Access to the source code. Your institution maintains control the program code lines. It can adapt it to their needs. According to the license affixed to the free and open source platform, institutions and developers are required or not to share the changes of the source code.

- Unlike to proprietary model. The open source license is free and defines the platform use terms.

- Community development. Communities develop each part of the free and open source platforms. The later promotes responsiveness when it comes to fix a bug or a security flaw.

- Economy. A null cost for the platform in the majority case of the free platforms downloadable on the internet.

\section{Evaluation methodology}

\subsection{Selection of platforms}

In this paper, we take care of four free e-learning platforms, which were selected in detail on 27 platforms. These platforms were selected from 650 platforms listed in the THOT CURSUS directory ${ }^{1}$.

Other platforms like Elgg, Dokeos, and WIMS..., are "encountered" in the work and are not cited as counted because: they are tools and not e-learning platforms in the sense of this study. In addition, their costs, their development status, their orientation, and the used technologies are too far from the axis of this study. We did a first filter on free platforms currently used in University or training structures. Next, we have elaborated a second filter according to the following criteria:

- Be operational and have been used by learners as part of lessons,

- Rely on new internet technologies, and meet the standards in force,

- Allow managing several types of pedagogical activities (reading, exercises, collaboration, communication...),

- Can manage a large number of users.

\footnotetext{
${ }^{1}$ THOT CURSUS is an e-learning platforms' directory, LMS, LCMS and other systems for content and learning management.
} 
- Enable the teachers and learners to create, organize and propose different types of activities (forum, wiki, blog...) as they like.

- Enable the teachers and learners to access and manage their interactions via these activities where and when they want according to their needs and objectives in terms of learning.

- Relies on well-founded and proven learning theories.

After applying the two filters, the study had focused on four listed e-learning platforms, namely: Atutor, Claroline Connect, Chamilo Connect, Efront, Formagri, Ilias, Moodle, Opigno and Sakai.

It should be recalled that this study was conducted in two stages:

- a census of platforms that matches the type of e-learning platforms, including the requested filters,

- Then, a detailed comparative study of the selected platforms.

Thus, to achieve our study, we opted for a qualitative approach consisting to realize an analysis by products exploration, analysis of documentation, collection of user opinions, discussions with publishers and simulation tests that we carried on the selected e-learning platforms. We present thereafter a common table we used to evaluate its e-learning platforms.

\subsection{Evaluation Approach}

To be used effectively, the selected e-learning platforms need an overall evaluation of the utility and usability specifications to be well exploited and used in the best conditions. Several evaluation methods of the platforms were encountered in literature $[17,14]$. However, they have not been chosen, because these studies focus mainly on the functional aspect, forgetting other aspects very important such as security, maintainability, portability, compatibility, performance efficiency and usability. For this reason, we have realized our own evaluation approach of the e-learning platforms quality. Table I present an overview of our approach with measures and criteria adapted for evaluation of the e-learning platforms.

This approach sets up tags for exploration of e-learning platforms. It organized and prepared our comparative study to assess e-learning platforms and allowed us to live the experience of distance training via a suitable platform on which we built our judgment of the relevance of the teaching and technological choices and meeting most of our expectations. Before applying this approach, we try to explain how to use it. 
Paper-LeaderTICE: A Platforms Recommendation System Based on a Comparative and Evaluative...

Table 1. Evaluation approach of the e-learning platforms quality [1]

\begin{tabular}{l}
\hline \multicolumn{1}{c}{ Assessment And Analysis Grid Of The E-Learning Platforms Quality } \\
\hline Platform Identification \\
\hline Platform designer: \\
\hline Platform type: \\
\hline Platform genre: \\
\hline Platform's pedagogical model: \\
\hline Platform license: \\
\hline Description: \\
\hline Version \& Edition: \\
\hline Used technology: \\
\hline Language: \\
\hline Website: \\
\hline \\
\hline Functional suitability tools \\
\hline Performance efficiency tools \\
\hline Compatibility tools \\
\hline Security tools \\
\hline Maintainability tools \\
\hline Portability tools \\
\hline Usability criteria \\
\hline
\end{tabular}

\subsection{Quality metric}

In order to verify that each e-learning platform meets the various criteria mentioned in the evaluation approach of the e-learning platforms quality.

We have mentioned in this study, that the metric for measuring the quality of an elearning platform will be the IS0 9126's conformity index [24]. Furthermore, we have implemented a rating system that gives a score ranging from 0 to 4 for each criteria, instead of 0 to 1 will therefore be adapted as follows: $\forall \mathrm{A}, \mathrm{B}, \mathrm{X}, \mathrm{Y} \in \mathbb{N}$

$\mathrm{CI}=\frac{\mathrm{A}}{B}=\frac{\sum x}{\sum y}=\frac{\sum \text { functional suitability scores }}{\sum \text { functional suitability attributes }}$

With $A \in[0,116], \mathrm{x}=2 \mathrm{n} \forall \mathrm{n} \in[0,2]$

$\mathrm{Or}$

$\mathrm{CI}=\frac{\mathrm{A}}{B}=\frac{\sum x}{\sum y}=\frac{\sum \text { performance efficiency scores }}{\sum \text { performance efficiency attributes }}$

With $\mathrm{A} \in[0,12], \mathrm{x}=2 \mathrm{n} \forall \mathrm{n} \in[0,2]$

Or 


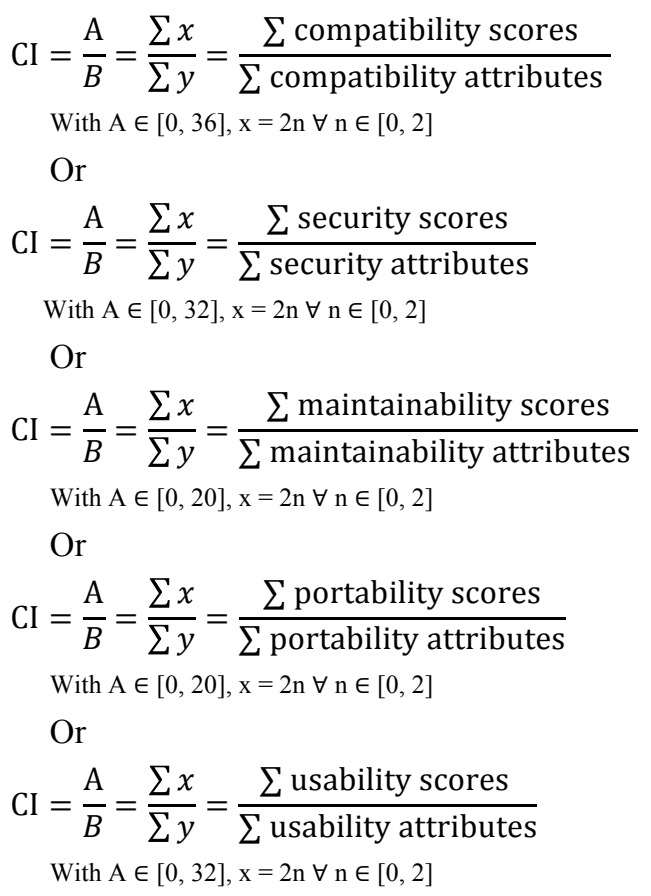

$\mathrm{CI}$ is the conformity index to the functional suitability, performance efficiency, compatibility, security, maintainability, portability, or usability requirements.

A is sum of the functional suitability, performance efficiency, compatibility, security, maintainability, portability or usability scores.

$\mathrm{X}$ is the functional suitability, performance efficiency, compatibility, security, maintainability, portability or usability scores. Each score has a value selected in our case between 0 and 4 is defined according to the following scale:

- 4: means that the platform fully satisfies to this characteristic (or subcharacteristic).

- 2: means that the platform partially satisfies to this characteristic (or subcharacteristic).

- 0: means that the platform does not satisfies to this characteristic (or subcharacteristic).

B is the number of the functional suitability, performance efficiency, compatibility, security, maintainability, portability or usability attributes.

$\mathrm{Y}$ is the functional suitability, performance efficiency, compatibility, security, maintainability, portability or usability attributes.

Given that $0 \leq \mathrm{CI} \leq 4$, more the $\mathrm{CI}$ value is near to its maximum 4 and more the $\mathrm{CI}$ index will comply with the standard requirements for the investigated characteristic. This index can also be expressed as a percentage rather than in absolute value (between 0 and 4) because the relative value in percentage makes it easier the index interpretation. For example, if $\mathrm{CI}=3$ then, we can say that the CI conformity index 
meets to $75 \%(3 / 4)$ of the standard requirements for the given characteristic or subcharacteristic. Consequently, the quality measuring metric of an e-learning platform will be calculated as following:

$$
\mathrm{Qm}=\frac{\sum \text { utility and/or usability scores }}{\sum \text { utility and/or usability attributes }}
$$

\subsection{Quality level}

In this study, we are assessing the overall quality level of the designed platforms to be integrated into distance-learning field. This following evaluation type, allows having a general idea about of the quality level of the evaluated e-learning platforms.

Table 2. Description of the appropriate quality level for each obtained score note

\begin{tabular}{l|l|l}
\hline Overall Score & \multicolumn{1}{|c}{ Overall Capacity (\%) } & \multicolumn{1}{c}{ Quality Level } \\
\hline $217 \Rightarrow 268$ & From $81 \%$ to $100 \%$ & $\begin{array}{l}\text { Very good: This score level allows us to achieve an } \\
\text { excellent level of quality for educational use since it meets } \\
\text { the required quality criteria. }\end{array}$ \\
\hline $163 \Rightarrow 216$ & From $61 \%$ to $80 \%$ & $\begin{array}{l}\text { Good: The platform is sufficient and adequate for an } \\
\text { educational use, although it does not allow a pedagogical } \\
\text { exploitation to full potential. }\end{array}$ \\
\hline $109 \Rightarrow 162$ & From $41 \%$ to $60 \%$ & $\begin{array}{l}\text { Average: The platform can be used in teaching and } \\
\text { learning, but it does not allow a sufficiently significant } \\
\text { educational use. }\end{array}$ \\
\hline $0 \Rightarrow 108$ & From $0 \%$ to $40 \%$ & $\begin{array}{l}\text { Substandard: The platform is far from being used in a } \\
\text { teaching and learning context since it does not meet the } \\
\text { criteria expressed. }\end{array}$ \\
\hline
\end{tabular}

The selected platforms are presented in the next section, with their identification, their general characterization, their strong and weak points. Moreover, this, using with a critical analysis based on the evaluation approach of the e-learning platforms quality presented in the Table 1.

\section{Platforms' comparison}

In this section, we will do a comparison of the selected e-learning platforms by using critical analysis, based on an evaluation approach presented in table I. The latter present an overview of the utility and usability dimensions with the measurements and adapted criteria for the e-learning platforms' evaluation (Appendix, Table 3).

\subsection{Identification of platforms}

Before proceeding to a global evaluation, we begin with identifying the selected elearning platforms to get an idea about their quality levels and ability to be used in distance learning. 


\subsection{Utility specifications analysis}

In the development of interactive software, the best-known utility criteria were presented in this section. Moreover, in the following, we present the essential criteria for the utility analysis, as well as the analyzed e-learning platforms.

Functional suitability. Functional suitability which means the degree to which a product or system provides functions that meet stated and implied needs when used under specified conditions [28]. Table 4 (Appendix) projects the essential functionalities for functional suitability analysis, as well as the analyzed e-learning platforms.

Performance efficiency. Performance efficiency, which means the performance relative to the amount of resources used under stated conditions [28]. In Table 5 (Appendix), we project the essential functionalities for performance efficiency analysis, as well as the analyzed e-learning platforms.

Compatibility. Compatibility which signifies the degree to which a product, system or component can exchange information with other products, systems or components, and/or perform its required functions, while sharing the same hardware or software environment [28]. Table 6 (Appendix) presents the essential functionalities for compatibility analysis, as well as the analyzed e-learning platforms.

Security. Security which means the degree to which a product or system protects information and data so persons or other products or systems have the degree of data access appropriate to their types and levels of authorization [28]. Table 7 shows the essential functionalities for security analysis, as well as the analyzed e-learning platforms.

Maintainability. Maintainability. It means the degree of effectiveness and efficiency with which a product or system can be modified by the intended maintainers [28]. In Table 8 (Appendix), the essential functionalities for maintainability analysis, as well as the analyzed e-learning platforms.

Portability. Portability which signifies the degree of effectiveness and efficiency with which a system, product or component can be transferred from one hardware, software or other operational or usage environment to another [28]. Table 9 shows the essential functionalities for portability analysis, as well as the analyzed e-learning platforms.

\subsection{Usability specifications analysis}

Usability refers to means the degree to which a product or system can be used by specified users to achieve specified goals with effectiveness, efficiency and satisfaction in a specified context of use [28]. Table 10 (Appendix) projects the essential functionalities for usability analysis, as well as the analysed e-learning platforms.

\section{$5 \quad$ Platforms' evaluation}

After applying proposed approach and analyzing the selected e-learning platforms by assigning a score for each criteria. We obtained the following results. 


\subsection{Comparison results}

We achieved overall scores between 180 and 252, which mean that the e-learning platforms have reached between $67 \%$ and $94 \%$ of the criteria. The percentages that reflects the platforms' quality levels regarding the analysis and evaluation of each dimension. Consequently, we obtained the presented results in the Table 11 (Appendix).

Analyzed platforms, present each with a philosophy, interesting pedagogical conceptual references, different benefits and special characteristics, which all offering a set of functionalities allowing educational institutions to put online training courses.

Moodle, Sakai, Opigno, and Atutor are platforms that present a very good utility and usability degree.

Moodle provides, operationally, the greatest functional and pedagogical wealth for learners and teachers as it is shown in table XI. This platform offers a plagiarism detection module, as well as other important educational tools.

The platform is centered on the social constructivism ${ }^{2}$, it is extremely modular, and the platform is suitable for all structures. Thus, we obtained the following results:

We got a $4(100 \%)$ compliance index regarding maintainability, security, and usability. In addition, this reflects that these Moodle's specifications are fully satisfied for educational use. Moreover, we got a: 3.86 (97\%) functional suitability, $3.6(90 \%)$ portability, 3.33 (83\%) compatibility, and 2.67 (67\%) effective performance compliance index. This reflects that these Moodle's specifications are sufficient for good pedagogy. Consequently, we obtained a 252 overall score, which means that the platform has $94 \%$ reached criteria, a percentage that reflects the platform quality level. This level allows Moodle to achieve an excellent quality level for educational use.

Sakai offers a very important functional and pedagogical wealth. The platform is centered on constructivism ${ }^{3}$ and it is extremely modular. Notably, we obtained the following results:

We got a: 3,75 (94\%) usability and security, 3,66 (92\%) functional suitability, 3,6 (90\%) maintainability, 3,2 (80\%) portability, and 2.67 (67\%) compatibility and effective performance compliance index. This reflects that these Sakai's specifications are sufficient for good pedagogy. Consequently, we obtained a 232 overall score, which means that the platform has $87 \%$ reached criteria, a percentage that reflects the platform quality level. This level allows Sakai to achieve a very good quality level for educational use.

Opigno offers a very important pedagogical wealth, for the learning support and for the design and the conduct of the teachings. Opigno is centered on traditional pedagogy ${ }^{4}$, it is extremely modular. Notably, we obtained the following results:

\footnotetext{
2 Social constructivism is centered on the learner. The learner learns through its representations. The construction of a knowledge although personal is carried out in a social setting. The context and come from both what we think and what others bring as interactions.

${ }^{3}$ Constructivism is a learning pedagogy based on the idea that the learner himself builds knowledge based on a mental activity. Constructivism is based on the assumption that, by reflecting on our experiences, we construct our own vision of the world in which we live.

4 Traditional pedagogy is that of the transmissive model. This pedagogy privileges the relationship between the teacher and the knowledge. In other words, the teacher exposes a knowledge in the form of a
} 
We got a $4(100 \%)$ compliance index regarding maintainability. In addition, this reflects that this Opigno's specification is fully satisfied for educational use. Moreover, we got a: 3,66 (92\%) functional suitability, 3,5 (88\%) usability, 3,25 (81\%) security, 2,89 (72\%) compatibility, $2,8(70 \%)$ portability, and 2,67 (67\%) effective performance compliance index. This reflects that these Opigno's specifications are sufficient for good pedagogy. Consequently, we obtained a 228 overall score, which means that the platform has $85 \%$ reached criteria, a percentage that reflects the platform quality level. This level allows Opigno to achieve a very good quality level for educational use.

Atutor offers a very important functional wealth. The platform is centered on traditional pedagogy, it is extremely modular. Notably, we obtained the following results:

We got a $4(100 \%)$ compliance index regarding security. In addition, this reflect that this Atutor's specification is fully satisfied for educational use. Moreover, we got a: 3,52 (88\%) functional suitability, 3,25 (81\%) usability, 3,11 (78\%) compatibility, and $2,4(60 \%)$ portability and maintainability compliance index. This reflects that these Atutor's specifications are sufficient for good pedagogy. Furthermore, we got a $2(50 \%)$ effective performance compliance index. This reflects that this Atutor's specification is partially sufficient for educational use. Consequently, we obtained a 218 overall score, which means that the platform has $81 \%$ reached criteria, a percentage that reflects the platform quality level. This level allows Atutor to achieve a very good quality level for educational use.

Ilias, Efront, Claroline Connect, Chamilo Connect and Formagri are platforms that present a good utility and usability degree.

Ilias allows some sharing of tasks between teachers and offers important functionalities. The platform is centered on the social constructivism. It is extremely modular. Notably, we obtained the following results:

We got a: 3,59 (90\%) functional suitability, 3,5 (88\%) security, 3,2 (80\%) maintainability, 3 (75\%) usability, and 2,89 (72\%) compatibility compliance index. This reflects that these Ilias's specifications are sufficient for good pedagogy. Moreover, we got a $2(50 \%)$ effective performance and portability compliance index. This reflects that these Ilias's specifications are partially sufficient for educational use. Consequently, we obtained a 214 overall score, which means that the platform has $80 \%$ reached criteria, a percentage that reflects the platform quality level. This level allows Ilias to achieve a good quality level for educational use.

Efront offers important functionalities. The platform is centered on the traditional pedagogy. It is extremely modular. Notably, we obtained the following results:

We got a $4(100 \%)$ compliance index regarding security. In addition, this reflect that this Efront's specification is fully satisfied for educational use. Moreover, we got a: 3,75 (94\%) usability, 3,45 (86\%) functional suitability, 2,67 (67\%) compatibility, and 2,4 $(60 \%)$ maintainability compliance index. This reflects that these Efront's specifications are sufficient for good pedagogy. Furthermore, we got a: 2 (50\%) effective performance, and 1,6 (40\%) portability compliance index. This reflects that these Efront's specifications are partially sufficient for educational use. Consequently,

lecturing, usually followed by exercises and / or lessons to be learned. The learner must integrate and apply the exposed knowledge by the teacher. 


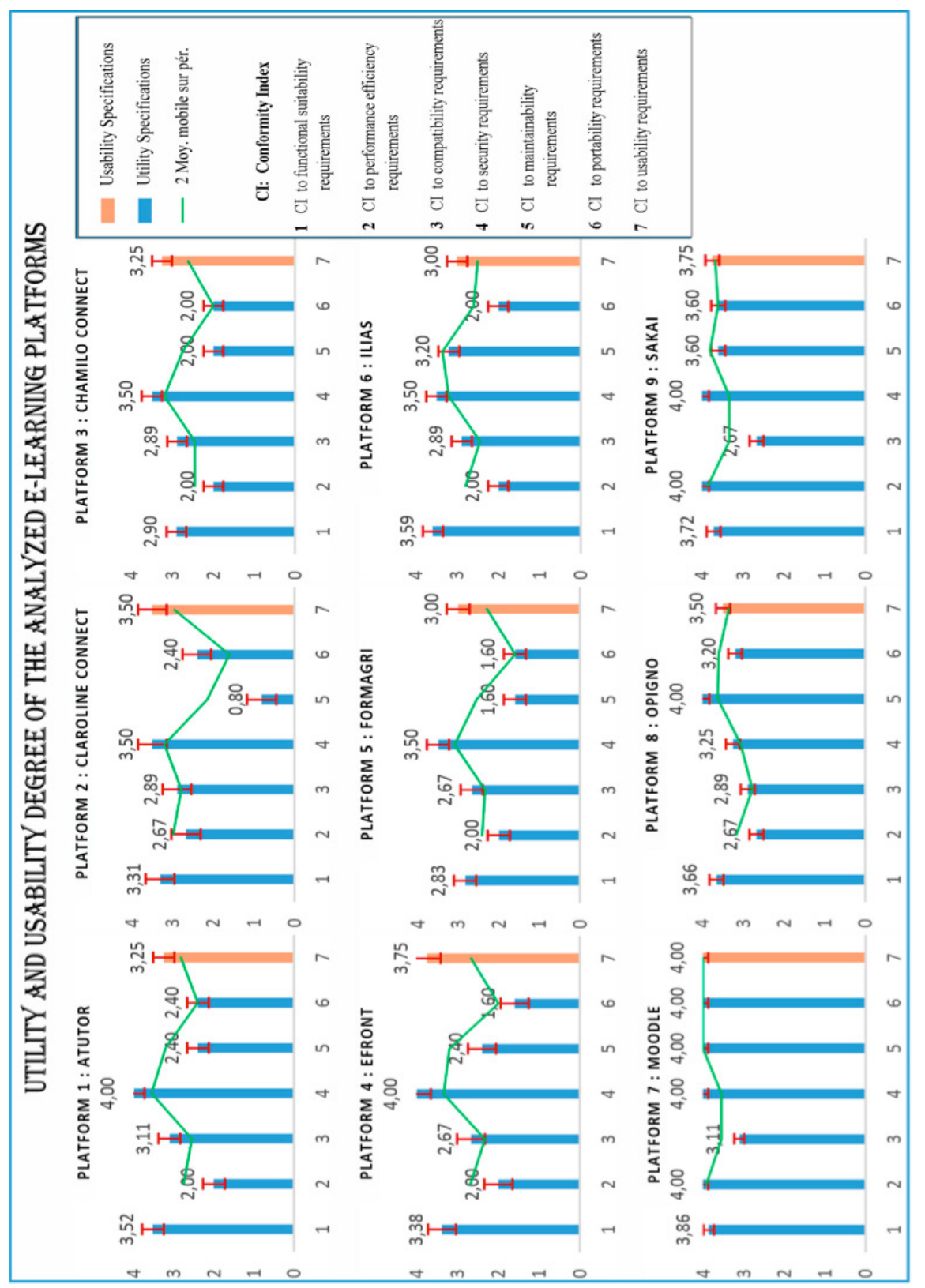

Fig. 2. The utility and usability degree for analyzed e-learning platforms, turn by turn, in each figure, the $\mathrm{x}$-axis represents certain conformities indices to the utility and usability requirements for each platform. These preliminary indices are presented in the Subfigures by a numbering from one to seven. Thus, the y-axis represents the values of these indices. In our study, these values are between zero and four. 
we obtained a 212 overall score, which means that the platform has $79 \%$ reached criteria, a percentage that reflects the platform quality level. This level allows Efront's to achieve a good quality level for educational use.

Claroline Connect offers important functionalities. The platform is centered on the social constructivism. It allows some sharing of tasks between teachers, as well as interconnection and exchange of information with several Claroline Connect platform. Notably, we obtained the following results:

We got a: 3,5 (88\%) usability and security, 3,24 (81\%) functional suitability, 2,89 (72\%) compatibility, and 2,67 (67\%) effective performance compliance index. This reflects that these Claroline's specifications are sufficient for good pedagogy. Moreover, we got a $2(50 \%)$ portability compliance index. This reflects that this Claroline's specification is partially sufficient for educational use. Furthermore, we got a 0,8 (20 $\%$ maintainability compliance index. This reflects that this Claroline's specification is not sufficient for good pedagogy. Consequently, we obtained a 198 overall score, which means that the platform has $74 \%$ reached criteria, a percentage that reflects the platform quality level. This level allows Claroline Connect to achieve a good quality level for educational use.

Chamilo Connect offers important functionalities. The platform is centered on the social constructivism. It allows some sharing of tasks between teachers. Notably, we obtained the following results:

We got a: 3,25 (81\%) security and usability, 2,9 (73\%) functional suitability, and $2,89(72 \%)$ compatibility compliance index. This reflects that these Chamilo Connect specifications are sufficient for good pedagogy. Furthermore, we got a: 2 (50\%) effective performance, portability, and maintainability compliance index. This reflects that these Chamilo's specifications are partially sufficient for educational use. Consequently, we obtained a 188 overall score, which means that the platform has $70 \%$ reached criteria, a percentage that reflects the platform quality level. This level allows Chamilo Connect to achieve a good quality level for educational use.

Formagri offers important functionalities. The platform is centered on the traditional pedagogy. Notably, we obtained the following results:

We got a: 3,25 (81\%) security, 3 (75\%) usability, 2,90 (73\%) functional suitability, and 2,67 (67\%) compatibility compliance index. This reflects that these Formagri specifications are sufficient for good pedagogy. Moreover, we got a: 2 (50\%) effective performance, and 1,6 (40\%) maintainability and portability compliance index. This reflects that these Formagri's specifications are partially sufficient for educational use. Consequently, we obtained a 180 overall score, which means that the platform has $67 \%$ reached criteria, a percentage that reflects the platform quality level. This level allows Formagri to achieve a good quality level for educational use.

\subsection{Synthesis}

Figure 3 presents the general classification results of the analyzed e-learning platforms, according to utility and usability degree falling within our critical analysis of free e-learning platforms. The latter is based on the ISO 9126's quality measurement index [24]. 
These analyzed platforms offer an important pedagogical and functional wealth, for the learning support and designing. They also offer an improvement in the conduct of teachings, the construction and organization of elaborate formations. In addition, these platforms implement an interoperability management between multimedia teaching resources and platform.

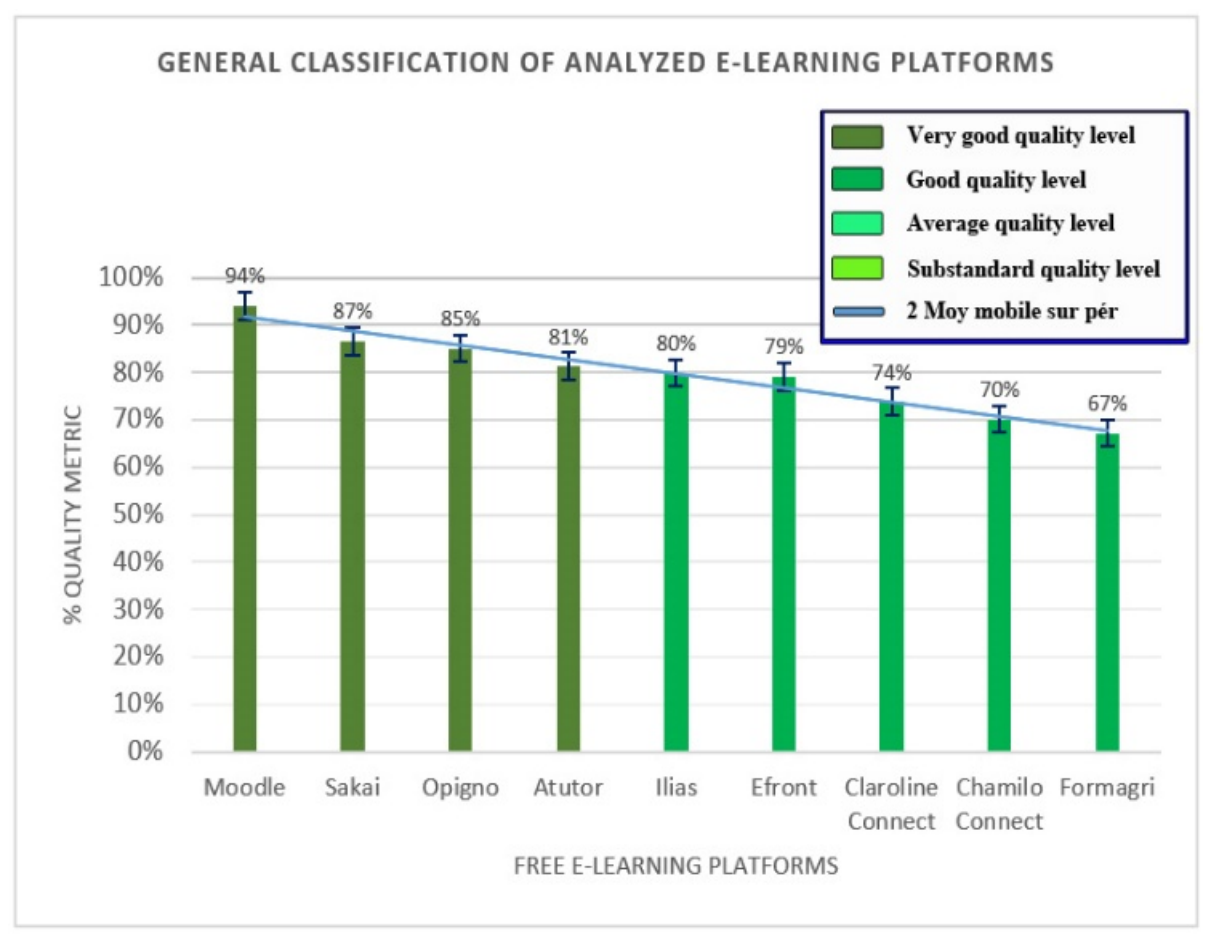

Fig. 3. General classification of the analyzed e-learning platforms, according to utility and usability degree

These platforms offer many options and authorize diverse usage scenarios, of which we see that the Moodle platform has overcome the list of platforms. Notably, it presents a very good utility and usability degree. Moodle has the ability to host thousands of learners, teachers and tutors. It is one of the most used free platforms in the world, with its large francophone and the international community, its clear, wellstructured and useful documentation. Its many discussion forums focusing on all problematic generated by the distance learning complexity. The Moodle platform based on the creation of learners' communities around with content and pedagogical activities. Moodle favors human exchanges, build communities of practices, and promotes mutual help and support between learners such as between teachers and tutors. Despite the utility and usability degree reached by the analyzed platforms, the result of the each platform evaluation shows that each has its own strengths and weaknesses. However, they have all unsatisfied needs on the pedagogical side, especially with regard to pedagogical conceptual references adopted by the platforms. Consequently, 
a new conceptual model of an e-learning platforms LMS is presented [34]. The model is based on the hybridization between four learning theories, namely the traditional pedagogy, the behaviorism, the cognitivist, and the social constructivism. Then, together with the main principles of these learning theories and the technical functionalities of the proposed LMS that result from the hybridization of these principles are outlined.

In the next section, we present our study results in the form of a recommendation system of free e-learning platforms according to the objectives and the specificities of any institution.

\section{LeaderTICE recommendation system}

LeaderTICE is a recommendation system of free e-learning platforms, that we implemented [29], in order to facilitate choosing the e-learning platforms, seeing that any random choice entails a money, effort and time loss. The system based on an approach $[1,6]$, which identifies the appropriate criteria to the specifications of any institution.

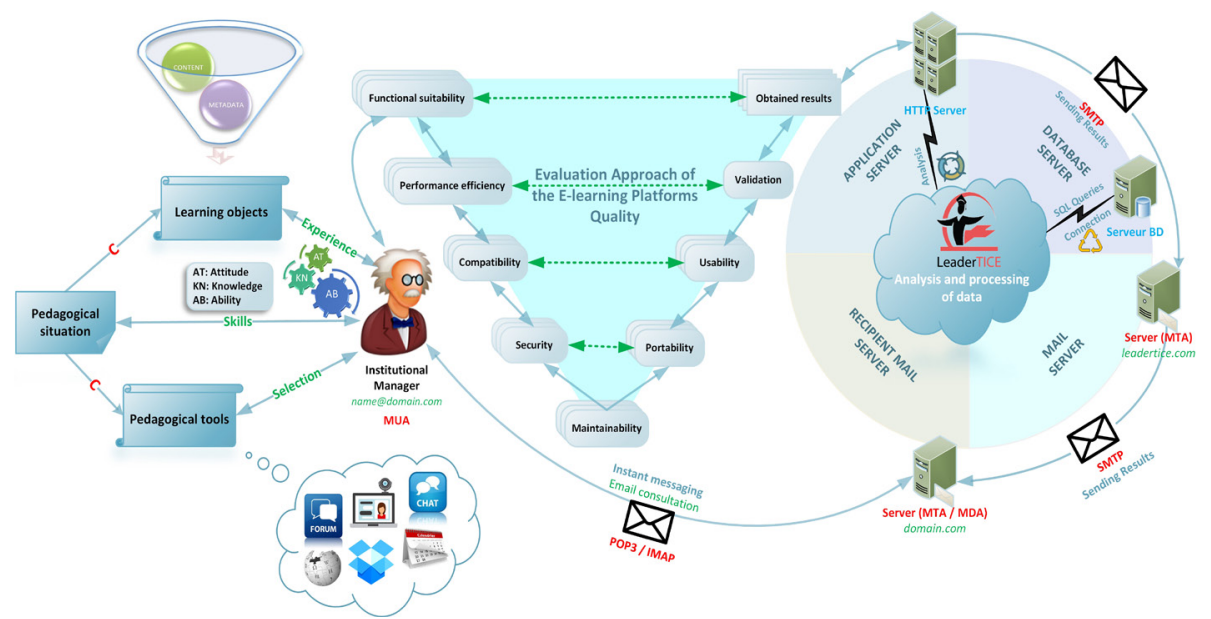

Fig. 4. Functional architecture of the LeaderTICE recommendation system of free e-learning platforms.

The system allows you choose the most suitable e-learning platform for your objects and your requested pedagogical tools. Moreover, this, according to the circuit shown in figure 4 . In the choice process, the formalization of needs will facilitate the selection of the e-learning platform that will allow the dissemination of trainings [5]. To choose the one that be integrated with our training ecosystem, we therefore, must arbitrate between:

- Pedagogical situation, which presents a genuine assumed, of simultaneous and complementary way, that a certain destabilization same time is a chosen fulcrum 
[25], after determining the objectives, specifying the pedagogical used method (expositive, interrogative ...) and the used supports (documents, video, image ...).

- Learning Objects, which present the smallest information units or smallest information processing tools used in a teaching context with a pedagogical intention aiming at facilitating the learning through technological support [23].

- Functional or organizational pedagogical tools... such as forum, wiki, videoconferencing, activities, tests, certification... corresponding to your pedagogical expectations and your teaching / learning situation.

- Financial implications, any wrong choice of e-learning platform will have financial repercussions.

After the formalization of the needs, the institutional manager has to choose the characteristics and pedagogical tools adapted to the institutional specificities, according to a questionnaire based on an evaluation approach of the e-learning platforms quality [1]. The latter presents an overview on the utility and usability dimensions with their adapted measures and criteria to evaluate e-learning platforms. This approach is mainly composed of seven characteristics, namely: functional suitability, performance efficiency, compatibility, security, maintainability, portability, and usability. Thus, it should be mentioned that you have the right to choose just the adapted characteristics and sub-characteristics to your institutional needs, your technical imperatives and your functional and organizational expectations.

After validating your choices, the system done the analysis and processing of obtained results by interpreted algorithmic programs via an application server (Apache HTTP $^{5}$ Server), who took charge of the analysis and processing of the code, and interconnection to the database. Thereafter, the application server sends the results obtained by the mailing way via the $\mathrm{SMTP}^{6}$ communication protocol, used to transfer the electronic mails towards the mail server. Furthermore, the $\mathrm{MTA}^{7}$ mail server responsible for transport, by its turn, returns the mail of received results by the application server by the mailing way via the SMTP communication protocol toward the MTA recipient's mail server. Lastly, the latter delivers, then, the mail that contains the result obtained in the incoming electronic mail server, which then stores the waiting mail that you use it via the POP3 / IMAP protocol.

\section{$7 \quad$ Conclusion and perspectives}

The subject of this paper is very important. In actually fact, the free platforms are, on the one hand, a topical domain in Software Engineering and Pedagogical Engineering Multimedia. On the other hand, the application of these platforms in e- learning reaches a vast clientele. Moreover, academically, it seems that it is interesting to apply for the first time an inspired approach of software engineering to evaluate the elearning platforms quality.

\footnotetext{
${ }^{5}$ HTTP : Hypertext Transfer Protocol

${ }^{6}$ SMTP : Simple Mail Transfer Protocol

${ }^{7}$ MTA : Mail Transfer Agent
} 
Indeed, platforms quality analysis, according to our own approach led to very interesting results. We see that most of the analyzed platforms were initially developed a decade ago, based on a classical training model. The teacher is the one who holds the knowledge and transmits it, according to different modalities, to future learners in order to the learning foster of these latter. They are mostly TMS (Teaching Management Systems), that is to say tools at the teacher service to create and manage courses rather than at the learner service and the learning process. They are always part in a logic, uniform, techno-centric, and cantoned architecture in a reduced learning conception, which advocates a particular pedagogical theory independently of others.

A platform choice, pledge of success and sustainability for the pedagogical device, which also seems in adequacy with the free e-learning platforms' philosophy and their community dynamic. Consequently, constructed a new platform, we seem ideal for implementing a first one of distance training devices centered on the user and his activity. The new platform we are looking at implementing will allow teachers and learners to create, organize and propose different types of activities (forum, wiki, blog...) as they like. Furthermore, they are able to access and manage their interactions via these activities where and when they want according to their needs and their objectives in learning terms. Our platform will be based on the idea that we should give the equal action possibilities to both teachers and learners of distributing their control on the platform. The latter will also give the place to the learner to learn and make himself an actor of his own learning.

In this perspective, an experiment is therefore indispensable to validate what has been developed in the context of this paper. Indeed, the latter will be based on the implementing results of a teaching and learning device in Moroccan university, based on a platform known as intelligent and anthropocentric relying on a reduced learning design, with a view to enhance distance learning.

\section{References}

[1] Ouadoud, M., Chkouri, M.Y., Nejjari, A., Kadiri, K.E.E., 2016. Studying and Analyzing the Evaluation Dimensions of E-learning Platforms Relying on a Software Engineering Approach. International Journal of Emerging Technologies in Learning (iJET) 11, 11-20. https://doi.org/10.3991/ijet.v11i1.4924

[2] Stallman, R., 2017. gnu.org [WWW Document]. URL http://www.gnu.org/gnu/ thegnuproject.html (Accessed 6.5.16).

[3] Free Software Foundation, 2017. gnu.org [WWW Document]. URL http://www.gnu.org/ philosophy/free-sw.fr.html (Accessed 4.11.17).

[4] Knoop, A.P., Groen, R., 2012. SCORM - Contrib: SCORM Player - Confluence [WWW Document]. URL https://confluence.sakaiproject.org/display/SCORMPLAYER/SCORM (Accessed 4.12.17).

[5] , M.Y., Nejjari, A., Kadiri, K.E.E., 2017. Exploring a Recommendation System of Free Elearning Platform: Functional Architecture of the System. International Journal of Emerging Technologies in Learning (iJET) 12, 219-226. https://dx.doi.org/10.3991/ijet.v12i02. 6381

[6] Ouadoud, M., Chkouri, M.Y., Nejjari, A., Kadiri, K.E.E., 2016. Studying and comparing the free e-learning platforms, in: 2016 4th IEEE International Colloquium on Information 
Paper-LeaderTICE: A Platforms Recommendation System Based on a Comparative and Evaluative...

Science and Technology (CiSt). Presented at the 2016 4th IEEE International Colloquium on Information Science and Technology (CiSt), pp. 581-586. https://doi.org/10.1109/ CIST.2016.7804953

[7] Dambreville, S.C., 2008. Evaluer un dispositif de formation à distance : Principes et retour d'expérience. Revue des Interactions Humaines Médiatisées $($ RIHM) = Journal of Human Mediated Interactions 9, 25-52.

[8] Galloy, S., Haas, C., Lodewijck, M., 2002, “Analyse d'environnements de formation à distance, " CIFoP - Le Centre Interuniversitaire de Formation Permanente.

[9] Graf, S., List, B., 2005. An evaluation of open source e-learning platforms stressing adaptation issues, in: Fifth IEEE International Conference on Advanced Learning Technologies (ICALT'05). Presented at the Fifth IEEE International Conference on Advanced Learning Technologies (ICALT'05), pp. 163-165. https://doi.org/10.1109/ICALT.2005.54

[10] Marquet, P., n.d, 2005. Lorsque le développement des TIC et l'évolution des théories de l'apprentissage se croisent. Savoirs, pp. 105-121. https://doi.org/10.3917/savo.009.0105

[11] Connect-i society, 2016. Opigno User Manual [WWW Document]. URL https://www.opigno.org/160707 Opigno User-Manual.pdf. (Accessed 4.12.17).

[12] El-Mawas, N., Oubahssi, L., and Laforcade, P., 2014. Étude comparative de plateformes de formation à distance. GRAPHIT-D2.5\&2.2.

[13] Kaddouri, M., Bouamri, A., 2010. Usage de plateformes d'enseignement à distance dans l'enseignement supérieur marocain : avantages pédagogiques et difficultés d'appropriation. Questions Vives. Recherches en éducation 107-118. https://doi.org/10.4000/questions vives. 642

[14] Aska, Le Préau and Klr.fr, 2000. Choisir une solution de téléformation : 2000 study: l'offre de plates-formes et de portails de téléformation » / [Study conducted by Bouthry, A., Chevalier, P., Ravet, S., and al.].

[15] Dooremont, F., 2014. Sakaï | Fiche logiciel validé PLUME, [WWW Document]. URL http://www.projet-plume.org/fiche/sakai. (Accessed 4.12.17).

[16] Moodle community, 2016. Fonctionnalités - MoodleDocs, [WWW Document]. URL https://docs.moodle.org/3x/fr/Fonctionnalités. (Accessed 4.12.17).

[17] Lablidi, A., Abourrich, A., and Talbi, M., 2009. Démarche préconisée pour évaluer une plate-forme, Association EPI, [WWW Document]. URL http://www.epi.asso.fr/revue/ articles/a0912b.htm. (Accessed 4.12.17).

[18] Escribano, M.A.E., 2010. Manual de Usuario ATutor 1.6.2. Unidad de Coordinación del Nodo Nacional de GBIF en España, [WWW Document]. URL http://www.atutor.ca/ atutor/docs/Manual ATutor v1.1 ES.pdf. (Accessed 4.12.17).

[19] ATutor community, 2016. ATutor: Learning Content Management System: Download, [WWW Document]. URL http://www.atutor.ca/atutor/modules. (Accessed 4.12.17).

[20] Claroline community, 2016. Introduction. Claroline Connect Documentation, [WWW Document]. URL https://claroline.gitbooks.io/claroline-connect-documentation/en/. (Accessed 4.12.17).

[21] DOGBE-SEMANOU, Koffi, DA., DURAND, A., LEPROUST, M., VANDERSTICHEL, H., 2007. Etude comparative de plates-formes de formation à distance. Le cadre du Projet@2L Octobre.

[22] The OVAREP (Observatoire des ressources multimédias), 2000. Étude comparative technique et pédagogique des plateformes pour la formation ouverte et à distance

[23] CREPUQ - Novasys, 2003. p. 133

[24] ISO/IEC 9126-3, 2003. Software Engineering - Software product quality - Part 3: Internal Metric

[25] Astolfi, J.- P., 1992. L'école pour apprendre. Paris, ESF 
Paper-LeaderTICE: A Platforms Recommendation System Based on a Comparative and Evaluative...

[26] Menasri, S., 2004. Etude comparative de plateformes d'enseignement en ligne (e-learning) utilisées dans un contexte universitaire [WWW Document]. URL http://urfist.enc. sorbonne.fr/anciensite/archives/gremi/gremi10juin04/comparatif.htm. (Accessed 4.12.17).

[27] Dimet, B., 2006. Etude comparative technique et pédagogique des plates-formes pour la formation ouverte et à distance, [WWW Document]. URL http://Www.portices.fr/forma tion/Res/-Formation/Plateformes/Pf1Resume.html. (Accessed 4.12.17).

[28] ISO/IEC 25010, 2011. Systems and software engineering -- Systems and software Quality Requirements and Evaluation (SQuaRE) - System and software quality models

[29] Ouadoud, M., 2016 LeaderTICE - About Us. [WWW Document]. URL http://leadertice.com/AproposDeNous. (Accessed 4.12.17).

[30] Gilbert, P., 2002. L'ingénierie pédagogique. Pour construire l'apprentissage en réseau.

[31] Whyte, A., and Federico, J., 2016. Home - Contrib: bigbluebutton - Confluence, [WWW Document]. URL http://confluence.sakaiproject.org/display/BBB/Home. (Accessed 4.12.17).

[32] Apereo Foundation, 2014. Features, Tools \& Functionality | Sakai, [WWW Document]. URL http://sakaiproject.org/features-tools-functionality. (Accessed 4.12.17).

[33] Apereo Foundation, 2014. Learning Management | Sakai, [WWW Document]. URL http://sakaiproject.org/learning-management. (Accessed 4.12.17).

[34] Ouadoud, M., Nejjari, A., Chkouri, M.Y., Kadiri, K.E.E., 2017. Educational modeling of a learning management system, in: 2017 International Conference on Electrical and Information Technologies (ICEIT). Presented at the 2017 International Conference on Electrical and Information Technologies (ICEIT), pp. 1-6. https://doi.org/10.1109/EITech.2017.8255247

\section{Authors}

Mohammed Ouadoud is a PhD Candidate in Computer sciences, at the Laboratory of Informatics, Research Operational and Statistic Applied (LIROSA) at Faculty of Sciences, Abdelmalek Essaadi University. He has a Master degree in Instructional design Multimedia engineering at the École Normale Supérieure of Martil, Morocco in 2013. His current research focuses on E-learning, Software Engineering, Man Machine Interface, Bigdata and Adaptive Hypermedia Systems. (E-mail: mohammed.ouadoud@gmail.com).

Mohamed Yassin Chkouri is with Laboratory of the Information System and Software Engineering (SIGL) at National School of Applied Sciences, Abdelmalek Essaadi University, Tetouan, Morocco. (E-mail: yassin.chkouri@gmail.com).

Amel Nejjari is with Laboratory of the Information System and Software Engineering (SIGL) at National School of Applied Sciences, Abdelmalek Essaadi University, Tetouan, Morocco. (E-mail: amelnejjari@yahoo.fr).

Article submitted 22 October 2017. Published as resubmitted by the authors 13 December 2017.

\section{Appendix}

See next pages. 
Paper-LeaderTICE: A Platforms Recommendation System Based on a Comparative and Evaluative...

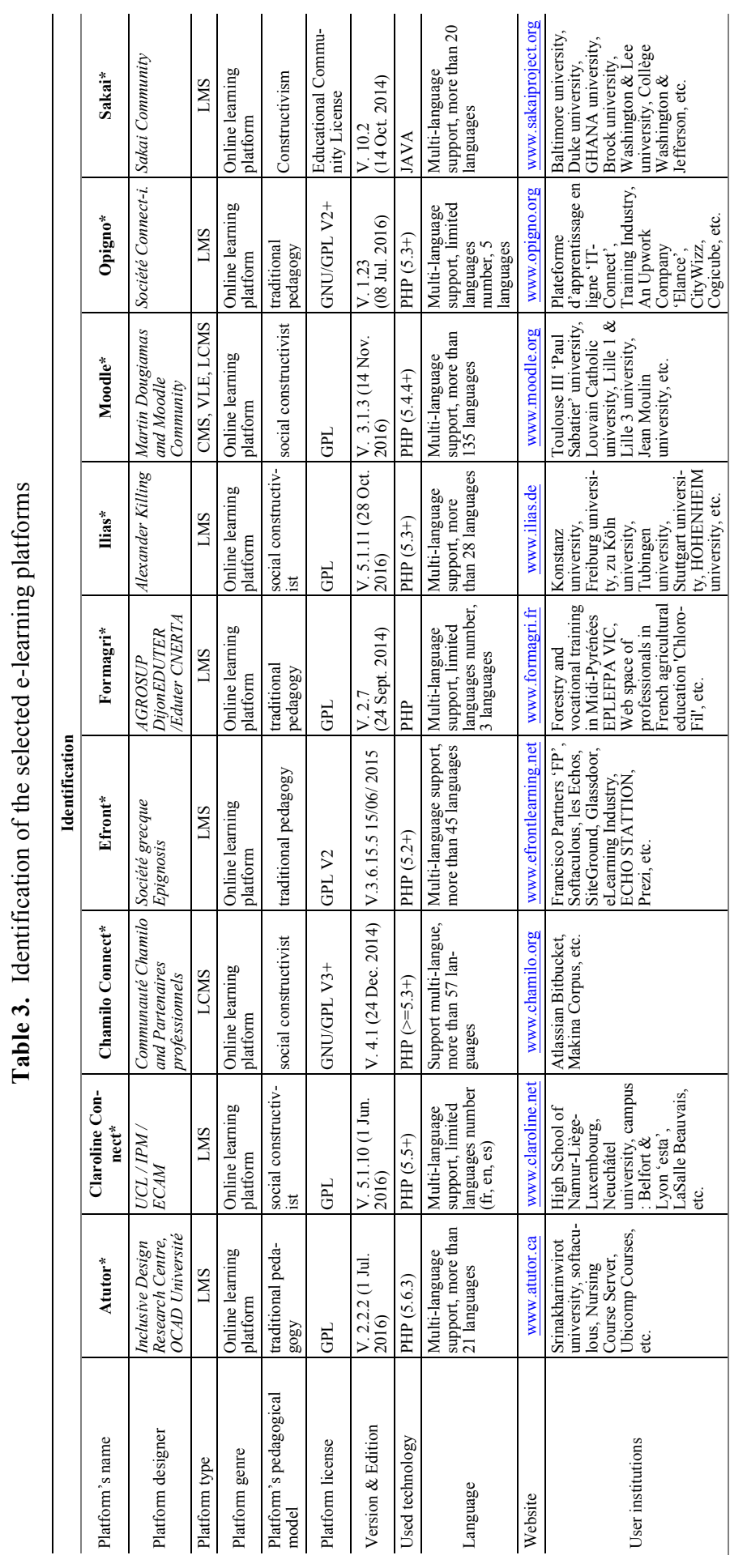


Paper-LeaderTICE: A Platforms Recommendation System Based on a Comparative and Evaluative...

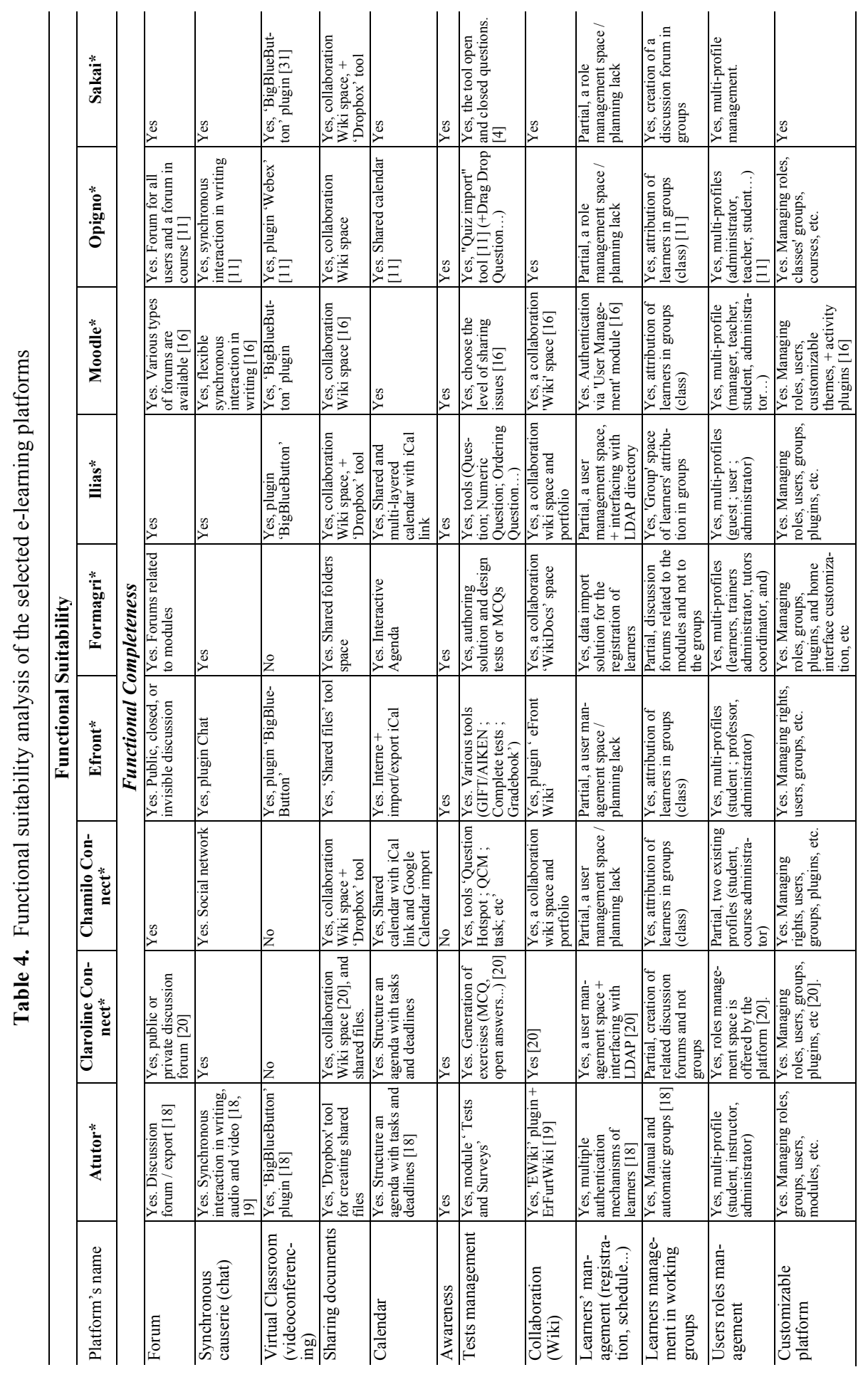


Paper-LeaderTICE: A Platforms Recommendation System Based on a Comparative and Evaluative..

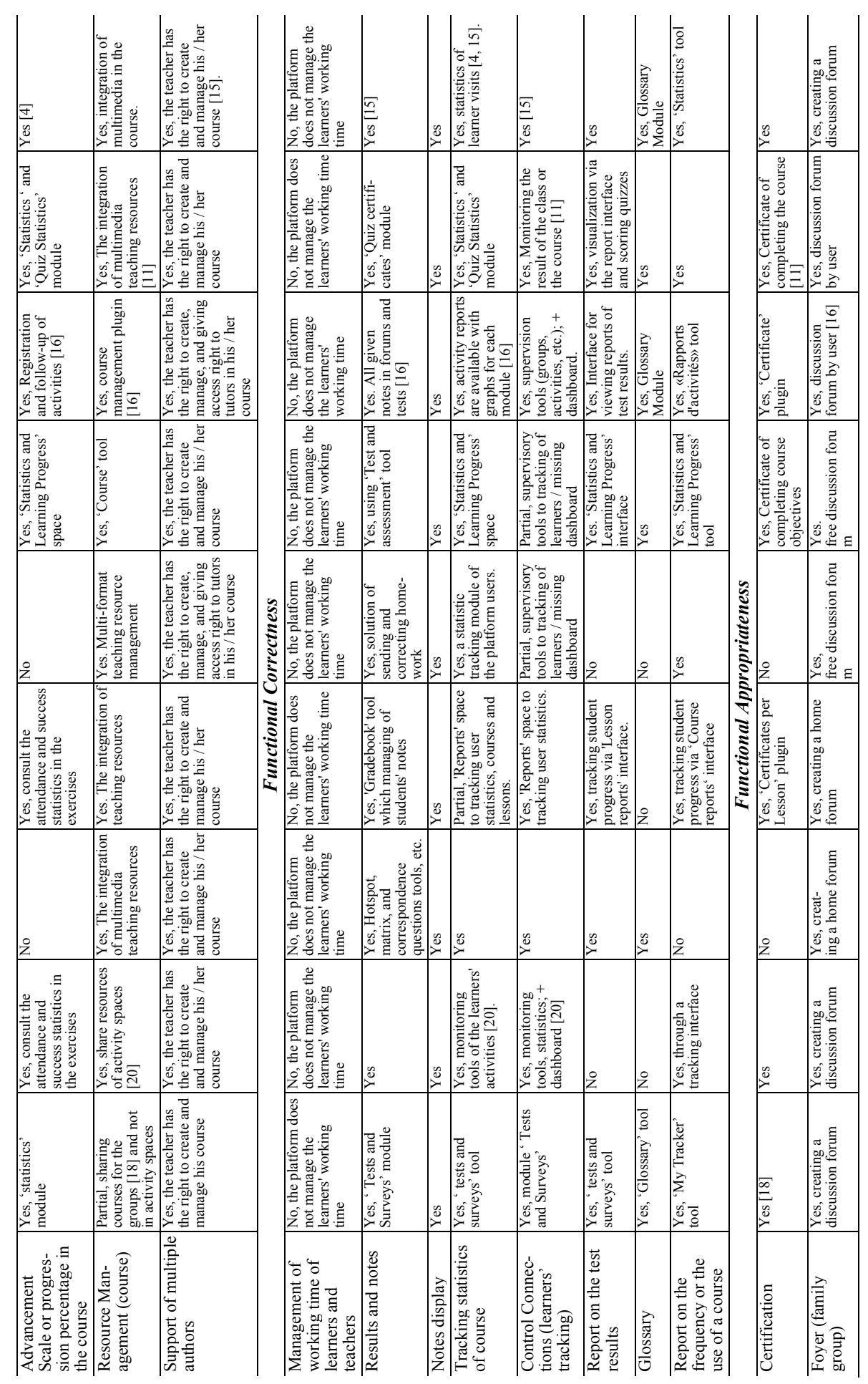


Paper-LeaderTICE: A Platforms Recommendation System Based on a Comparative and Evaluative...
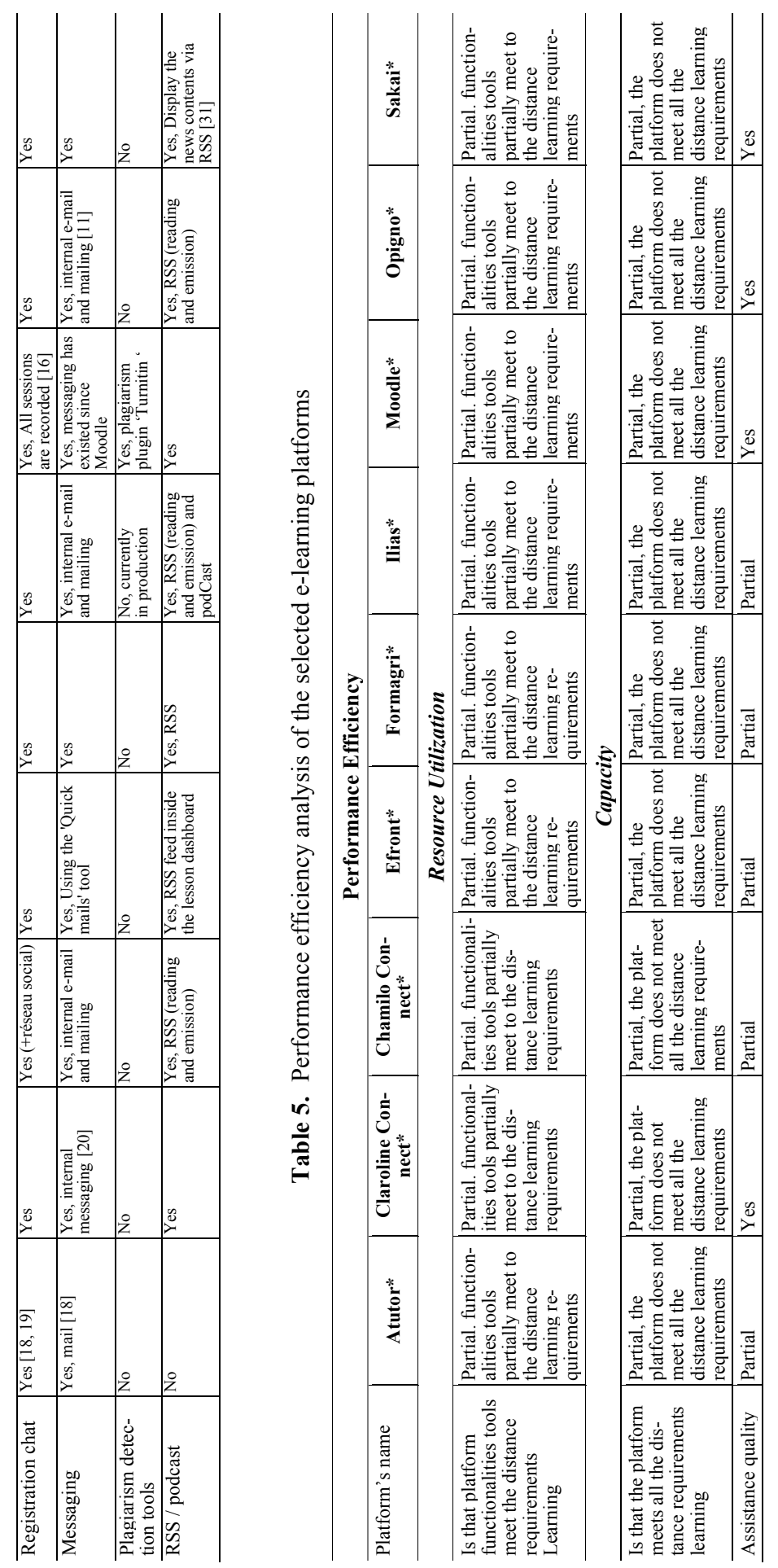
Paper-LeaderTICE: A Platforms Recommendation System Based on a Comparative and Evaluative...

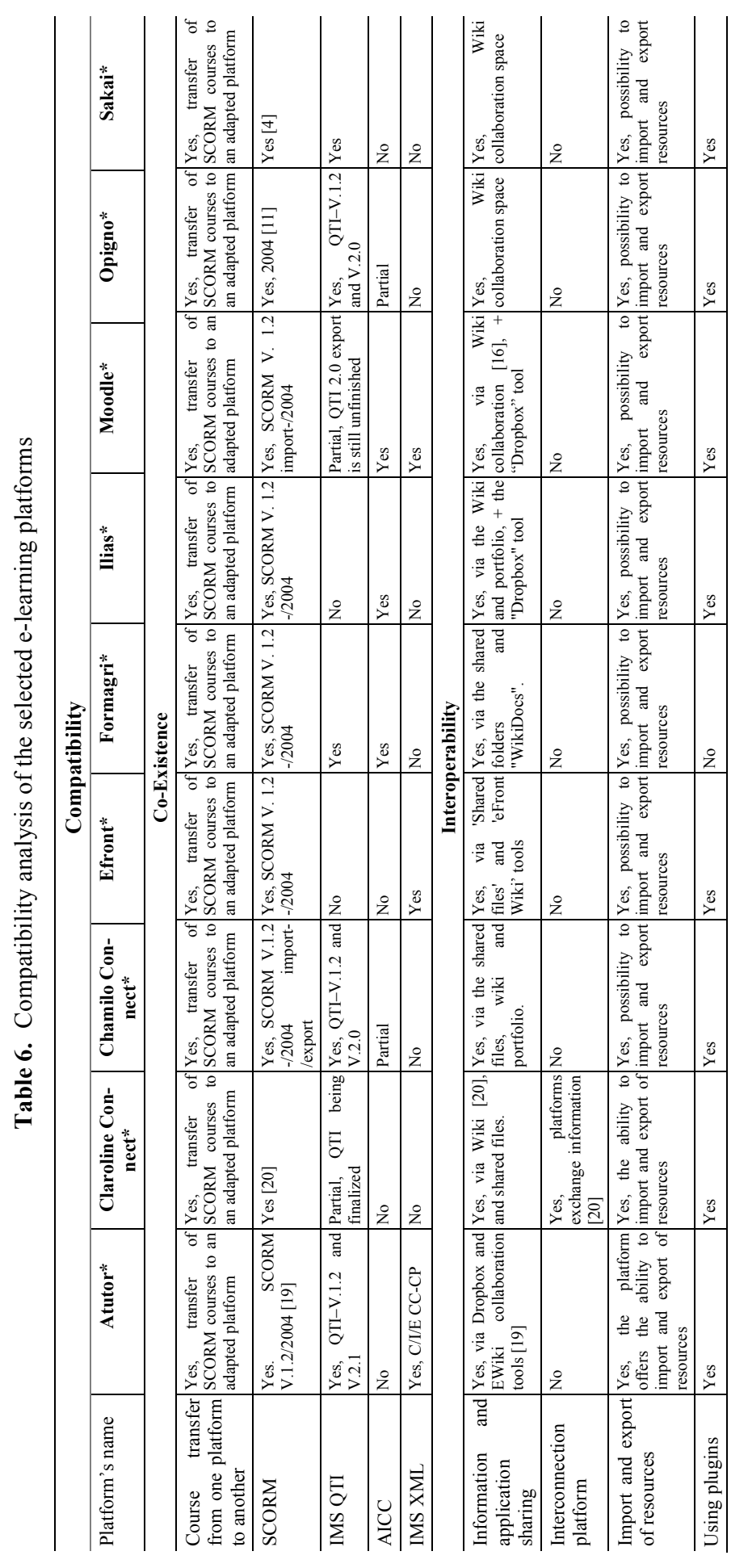


Paper-LeaderTICE: A Platforms Recommendation System Based on a Comparative and Evaluative...

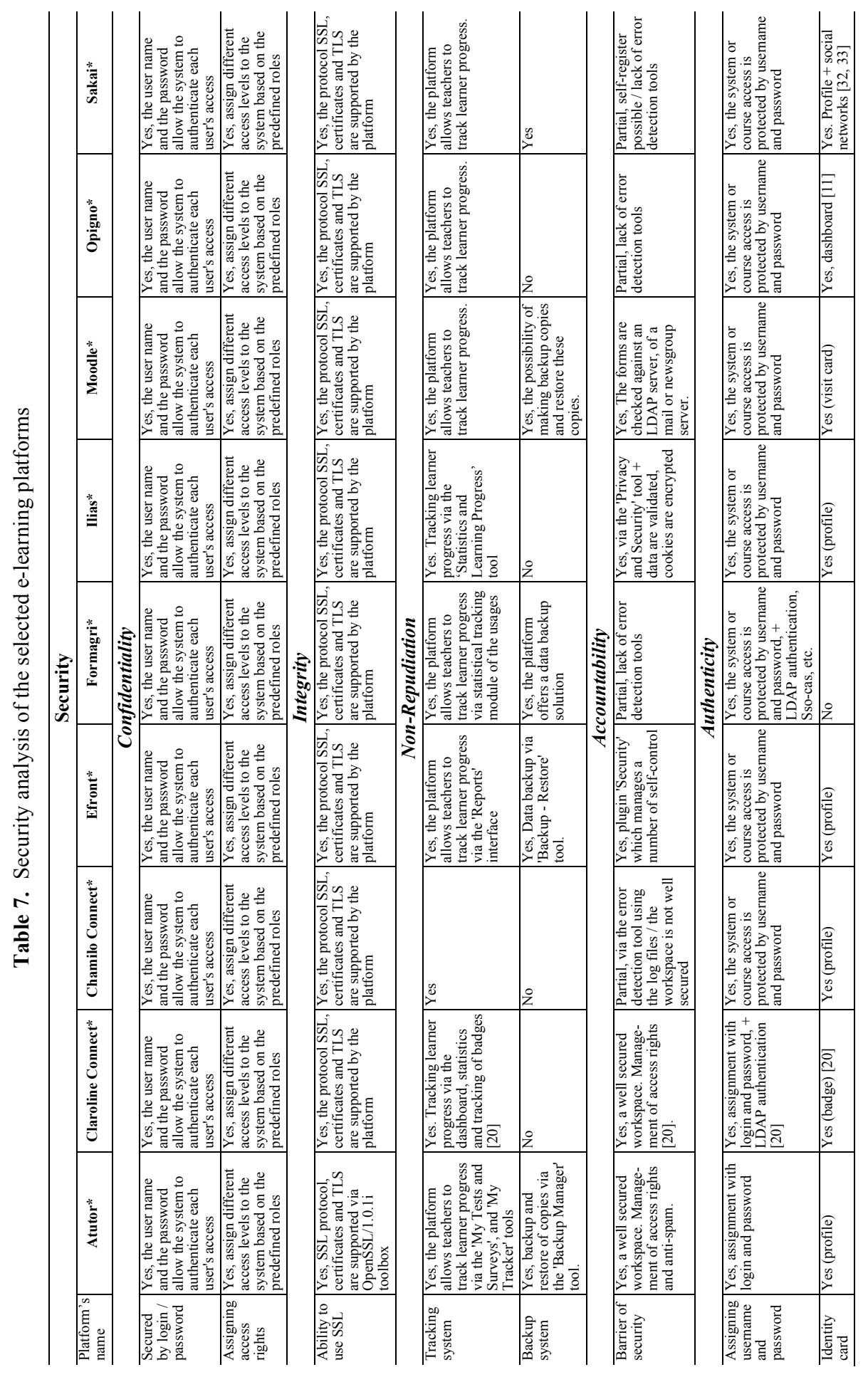


Paper-LeaderTICE: A Platforms Recommendation System Based on a Comparative and Evaluative...

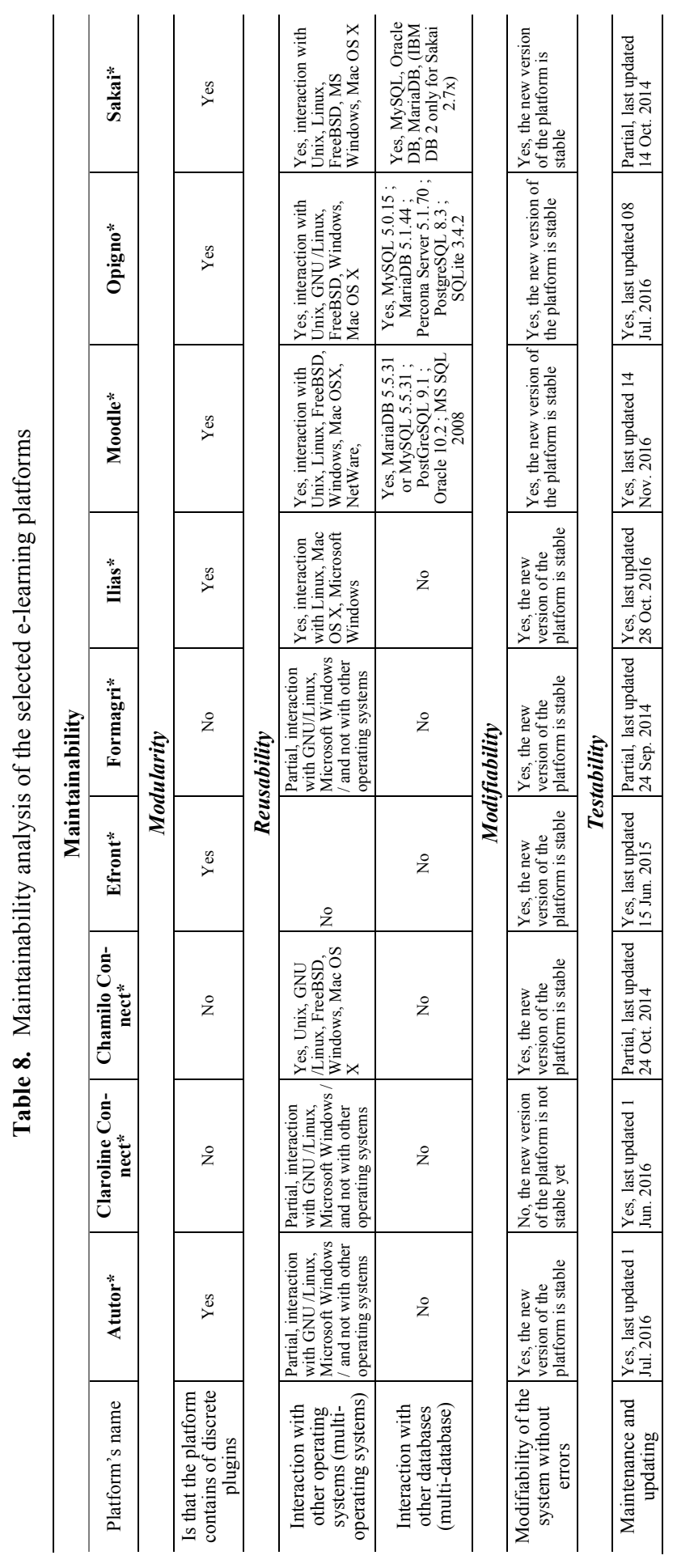


Paper-LeaderTICE: A Platforms Recommendation System Based on a Comparative and Evaluative...

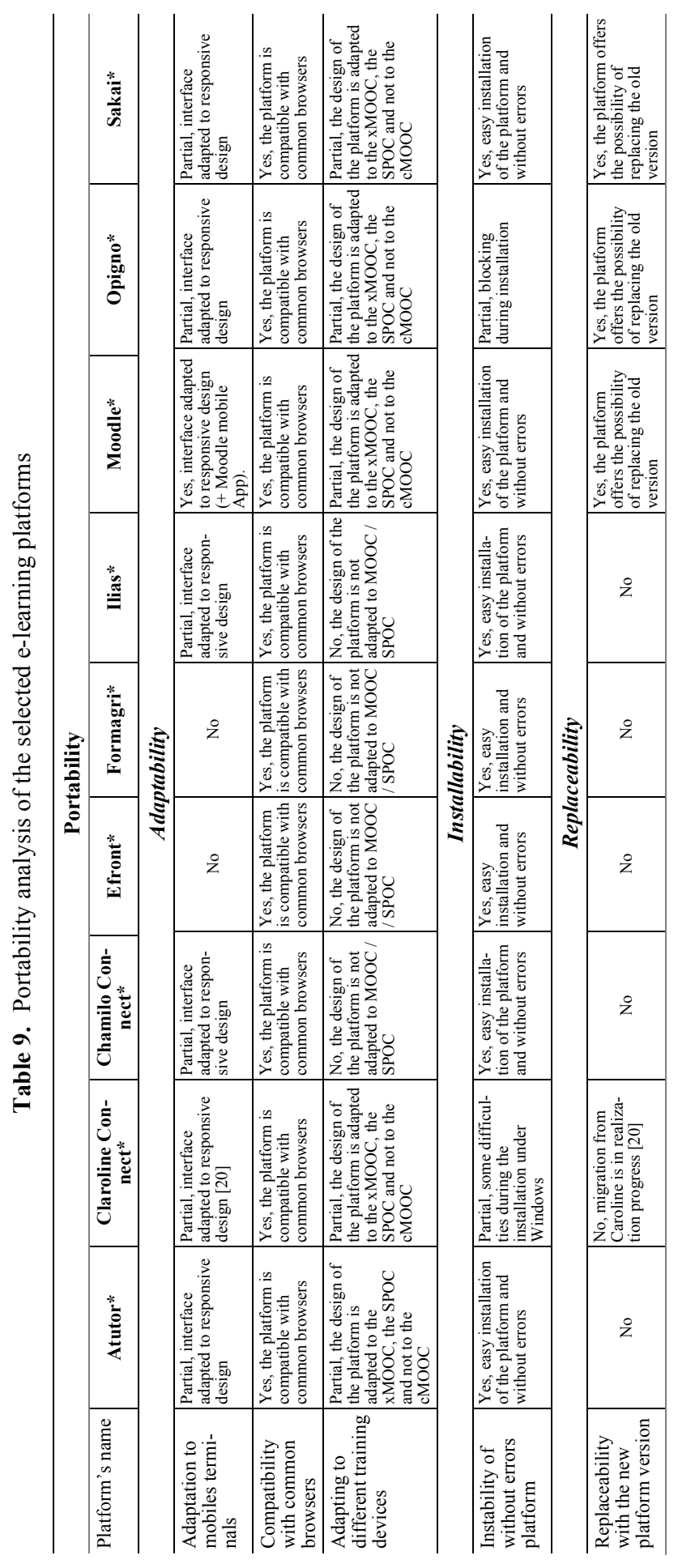


Paper-LeaderTICE: A Platforms Recommendation System Based on a Comparative and Evaluative...

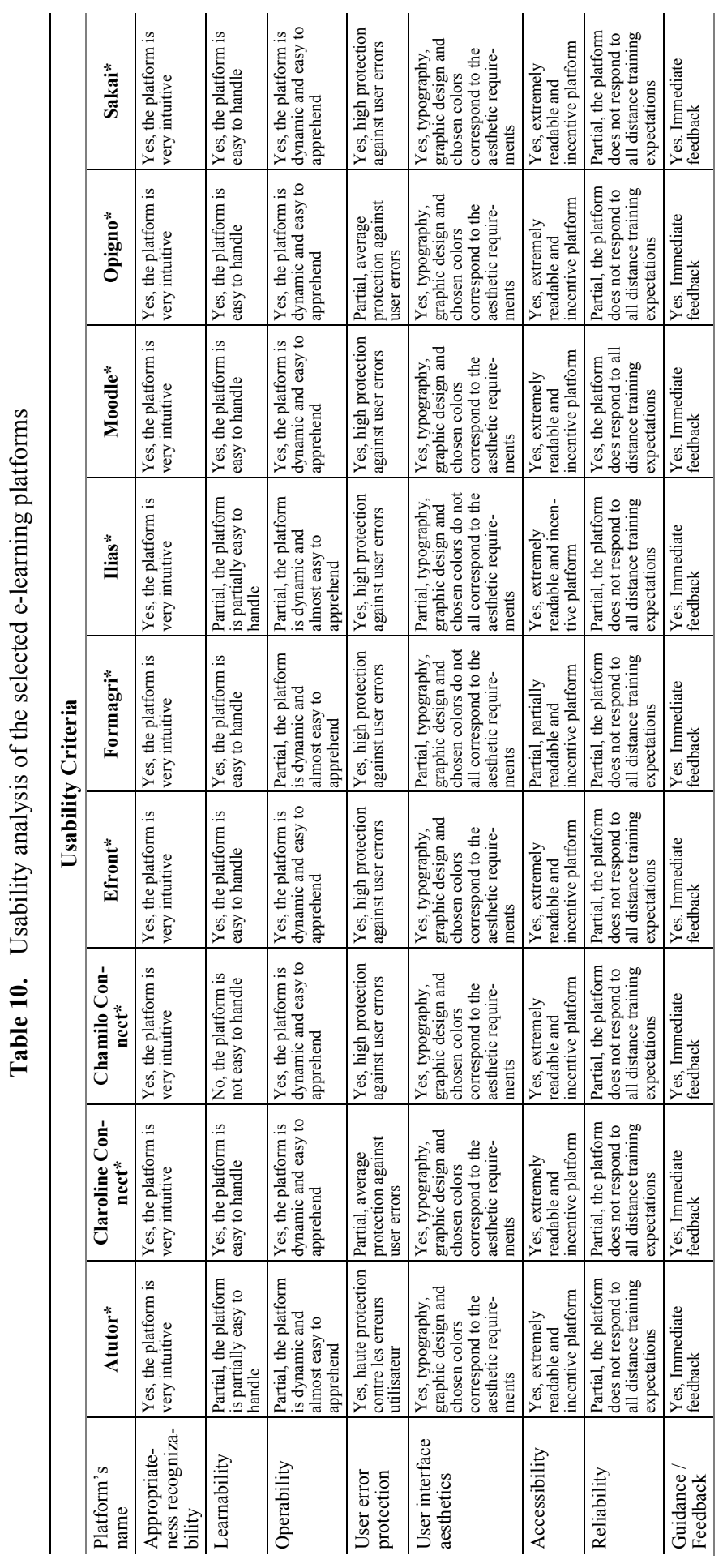


Paper-LeaderTICE: A Platforms Recommendation System Based on a Comparative and Evaluative...

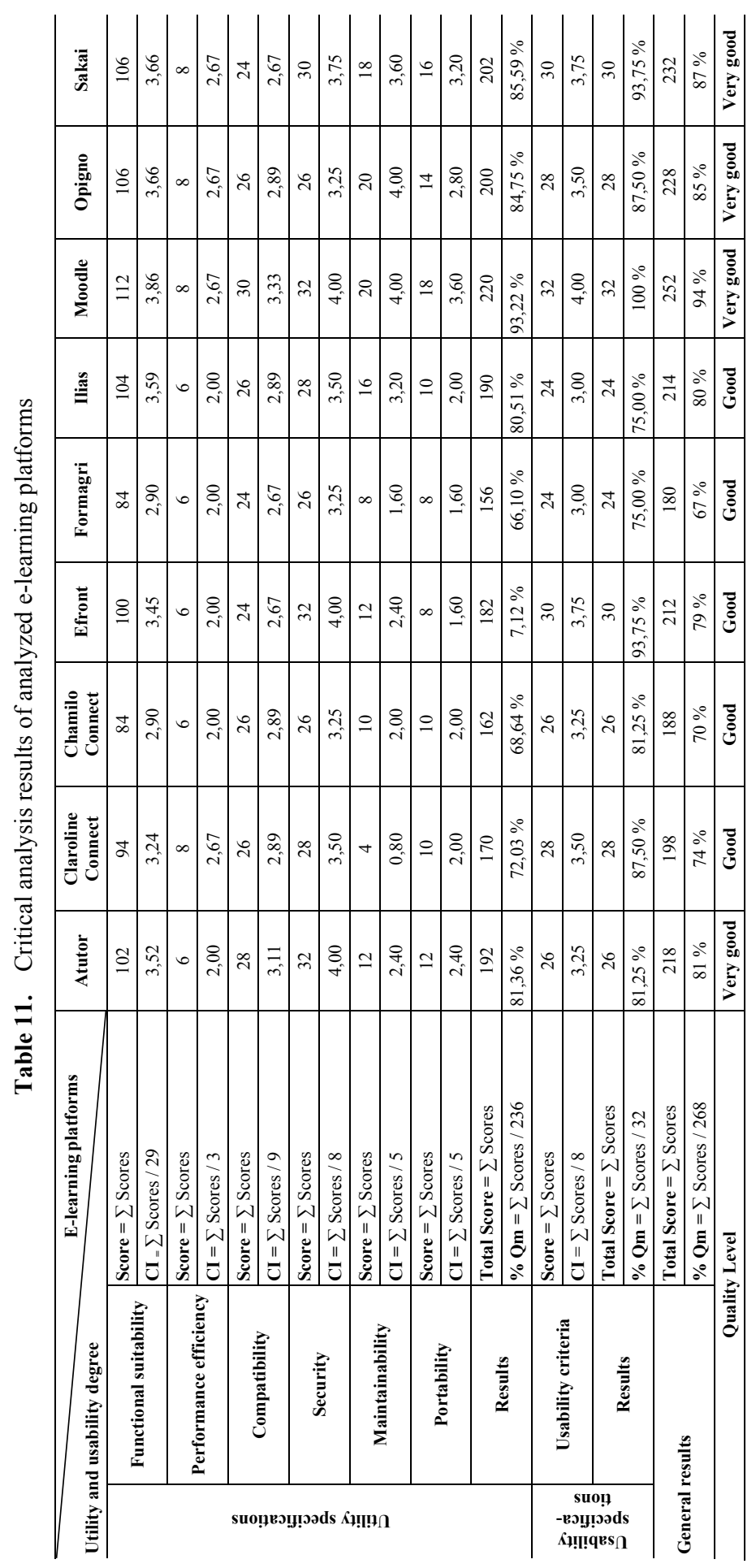

